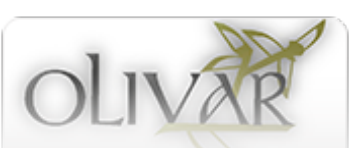

Olivar

ISSN: $1852-4478$

publicaciones@fahce.unlp.edu.ar

Universidad Nacional de La Plata

Argentina

\title{
María de los Ángeles González Briz, El Quijote en Uruguay: mito y apropiaciones, Montevideo, Ediciones Universitarias, Universidad de la República, 2017, 342 pp.
}

\author{
Calabrese, Martín Ezequiel \\ María de los Ángeles González Briz, El Quijote en Uruguay: mito y apropiaciones, Montevideo, Ediciones \\ Universitarias, Universidad de la República, 2017, 342 pp. \\ Olivar, vol. 19, núm. 30, 2019 \\ Universidad Nacional de La Plata, Argentina \\ DOI: https://doi.org/10.24215/18524478e070
}

Esta obra está bajo una Licencia Creative Commons Atribución-NoComercial-Compartirlgual 4.0 Internacional 
María de los Ángeles González Briz, El Quijote en Uruguay: mito y apropiaciones, Montevideo, Ediciones Universitarias, Universidad de la República, 2017, 342 pp.

Martin Ezequiel Calabrese

DOI: https://doi.org/10.24215/18524478e 070

IdIHCS, Facultad de Humanidades y Ciencias de la

Educación Universidad Nacional de La Plata, Argentina

Con el correr de los siglos, las investigaciones en torno a la obra cervantina han ido adquiriendo diferentes matices y vertientes que, sin dejar de atender el texto literario, se han focalizado en aspectos que las nuevas disciplinas, como la Historia del Libro y la Historia de la Lectura han puesto en el centro de la escena académica.

En este sentido, una considerable cantidad de investigadores han explorado minuciosamente los recorridos de la obra cervantina desde España hacia el resto de Europa y, a partir de la conquista de América, en las diferentes latitudes del sur. Al considerar los ejes espacial y temporal, la entidad de un libro, de una obra literaria, presenta una serie de particularidades que pueden ponerse en relación con otras naciones, pero que consignará siempre una impronta propia.

La recepción de la obra cervantina en Latinoamérica ha sido analizada de manera general a lo largo del siglo XIX y del siglo XX, pero no son frecuentes los estudios centrados en un país determinado. En su libro, la Dra. María de los Ángeles González Briz nos presenta una investigación que analiza las vicisitudes políticas y culturales de Uruguay, como Estado Nacional en formación, en relación con una obra literaria que se ha erigido como mito en dicho territorio y ha sido leída de manera simbólica, configurando características de la identidad nacional uruguaya.

El vínculo entre las naciones americanas con la hispanidad y la herencia cultural se ve atravesado a partir de las revoluciones independentistas del siglo XIX, motivo por el cual la relación colonial entra en conflicto. Esta contingencia política será punto de partida para diversos debates entre los miembros de la élites culturales americanasque por un lado niegan a España, pero por otro, reivindican algunos de sus clásicos literarios.

Fruto de los trabajos e investigaciones desarrollados en su carrera de Doctorado en la Universidad de Buenos Aires, este libro se propone como primer objetivo historiar la recepción del Quijote y sus diferentes tipos; analizar el impacto cultural de la obra, tanto en el ámbito literario, como por fuera de él; presentar una historia de la lectura del Quijote en el país rioplatense.

González Briz analiza cómo el Quijote fue leído y utilizado como símbolo en diferentes textos, excediendo el campo literario. Para ello recurre a diferentes materiales impresos que organiza de la siguiente manera:

a) Textos de ficción inspirados en el Quijote;

b) Textos críticos de interpretación y divulgación;

c) Textos que invocan algún aspecto del personaje o la fábula, asociados a la representación de Don Quijote, o quijotadas, y que forman el mito quijotesco.

En esta diversidad de materiales escritos, sistematizada en la "Introducción y delimitación de la cuestión" señala, a su vez, la existencia de casos híbridos y discursos asociados a los centenarios de la obra o del autor, comunicaciones públicas de diverso tipo. La autora esclarece en el segundo apartado del libro que en tanto símbolo, la obra y el personaje no se interpretan de manera unívoca, sino que el mismo símbolo fue utilizado con diferentes intereses y propósitos según los sujetos que lo utilizaban. Don Quijote, devenido en mito, pasó 
a ser un símbolo esgrimido desde el campo político, en discursos y escritos de diferentes líderes y, también, en el campo cultural, en notas periodísticas, eventos sociales, festividades y misceláneas. La autora da cuenta de la importante presencia de la obra en diversas bibliotecas, siendo este el primer modo de difusión de la obra a lo largo del siglo XIX. En las cuatro partes siguientes, González Briz profundiza los conceptos hasta aquí abordados.

La segunda parte, "La recepción americana y la construcción del mito Quijotesco" se ocupa principalmente de los vínculos políticos y culturales entre Uruguay y España, dando un panorama de las interpretaciones más representativas que tuvo el Quijote en la crítica literaria: la idea romántica de la novela; interpretaciones filológicas, filosóficas e interpretaciones de símbolos universales. Plantea como opuestos el flujo "regulador" de la filología que indaga en la interpretación original de la obra en su contexto de aparición, que suele replegarse y bastarse con el texto; y, por otro lado, el flujo "liberador", que encara la labor interpretativa considerando que las lecturas e interpretaciones necesariamente varían según los campos culturales en los que se lee, en diferentes momentos de la historia, el mismo texto.

El Quijote fue configurándose en Uruguay como un símbolo nacional a partir de la lectura romántica adoptada por la Generación del `98, más allá de la interpretación literaria, transformándose en símbolo filosófico, político e ideológico. El cambio de siglos representa una diferencia sustancial en la forma de interpretar la obra en España (atravesada por su desmoronamiento político y la total pérdida de dominaciones en el continente) y en América. En este sentido, las reescrituras americanas del Quijote fueron un modo de apropiación por parte de los escritores, una forma de recortar y tomas aspectos que sirvieran para identificarse.

En la tercera parte, "Centenarios cervantinos en Uruguay (siglo XX)" aborda una serie de materiales que analiza bajo la hipótesis de pensar los homenajes a Cervantes, anclados a los centenarios de las publicaciones de las obras cervantinas $(1905,1915,1916)$ y al centenario de su muerte $(1947)$ y de su nacimiento (1955). Intelectuales como Unamuno y Ortega y Gasset consolidan la idea de la obra cervantina como monumento literario para Occidente. González Briz afirma que estas fechas memorables funcionan como un "dispositivo de homenaje", y como disparadores de eventos, notas, artículos de opinión, ediciones, conmemoraciones, reescrituras. Estos homenajes se ven, a su vez, atravesados por los conflictos bélicos europeos y por el régimen franquista en España, que desencadena una serie de exilios de intelectuales y artistas hacia las tierras americanas. En las primeras décadas del siglo XX nuevamente hallaremos a España y a América interpretando al Quijote de maneras opuestas. El mito quijotesco presenta tal versatilidad que les permite, tanto a los franquistas como a los republicanos, utilizarlo según sus intereses.

Países como México, Argentina y Uruguay se presentan como un campo fértil para el desarrollo de diversos institutos y centros de investigación académicos, y los exiliados españoles son acogidos para ocupar cargos académicos y de dirección de institutos. En paralelo, decenas de imprenteros y editores viajan hacia el continente para concretar aquí sus proyectos editoriales, dándole principalmente a México y Argentina el capital simbólico necesario para consolidarse como centros editoriales y académicos de interés e influencia global.

En la cuarta parte del libro, "La Recepción del Quijote en la ficción" la autora da cuenta de una serie de obras literarias que se vinculan con el Quijote de diversos modos, publicadas en Uruguay y en otros países americanos a lo largo del siglo XX y principios del XXI, siendo Eduardo Galeano, Alberto Gallo y Marcelo Estefanell los más recientes. Su análisis parte de la casi imprescindible mención a Pierre Menard, de Borges, y da cuenta de una gran cantidad de textos ficcionales que toman algún aspecto del Quijote o que se plantean como continuaciones de la novela.

Finalmente, en la quinta parte, "Inscripciones de entresiglos: identificaciones, repeticiones y diferencias" se refiere a un nuevo distanciamiento entre Uruguay y el resto de Latinoamérica respecto de España, signado por un cambio de paradigma a la hora de entender la conquista española, no ya como un encuentro de culturas, sino como una invasión. A su vez, la incorporación de España a la Unión Europea, que repercutió en el endurecimiento de la política internacional y la migración de latinoamericanos a España. 
El libro de María Ángeles González Briz se presenta como una base sólida para indagar en la historia de la recepción de la novela cervantina, tanto en Uruguay como en el resto del continente, una propuesta rigurosa para indagar pormenorizadamente el recorrido de la novela más trascendental de la lengua española.

\section{BY-NC-SA}

